Chapter 6

\title{
Moderate Preterm Children Born at 32-36 Weeks Gestational Age Around 8 Years of Age: Differences Between Children with and Without Identified Developmental and School Problems
}

\author{
Anneloes L. van Baar, Marjanneke de Jong and \\ Marjolein Verhoeven
}

Additional information is available at the end of the chapter

http://dx.doi.org/10.5772/54623

\section{Introduction}

Preterm birth rates have been reported as $12 \%$ in the United States and 5-8\% in Europe, e.g. in The Netherlands [1, 2]. Mortality rates in preterm children decreased considerably in the last decades, especially for the extreme preterm born children $<28$ weeks' gestation [3]. However, $80-90 \%$ of the preterm children are born between 32 and 37 weeks' gestation: increasing birth rates in this subgroup have been reported for the last decades [4].Therefore, the number of surviving children increases, and morbidity and developmental outcome of these children become more important: for the children and their families, but also for societies. All preterm children are at increased risk for developmental problems, in all domains of development, with a gradient effect that children born earlier are at greater risk [5].

In recent years, more attention has been given to the development of moderate preterm born children. Moderate preterm birth between 32 and 36+6 weeks occurs in 6-9\% of all births [1, 2], which implies that many families are affected each year. Moderate preterm birth also constitutes an insult for the still immature brain of the infant. Several studies reported on outcome of moderate preterm children born between 32 through $36+6$ weeks.

A review showed that, overall, more school problems, less advanced cognitive functioning, more behavior problems, and a higher prevalence of psychiatric disorders was found in moderate and late preterm born infants, children, and adults compared with their full term peers [6]. 
Despite the fact that the risk for developmental problems of moderate preterm born children has become increasingly clear, not many systematic and long term follow up monitoring is done as yet. Further study is needed on the processes and factors that may shape the developmental trajectories of moderate preterm born children. Such information needs to provide guidelines to design an adequate monitoring program.

We studied a sample in The Netherlands of 377 moderate preterm born 7-9 year old children, who were not referred for neonatal intensive care treatment. Cognitive and emotional regulation difficulties were found to affect their functioning, as school problems, a slightly lower IQ, attention and behavioral problems appeared when the moderate preterm children were compared with 182 term born children [7]. Lower educational attainment and more specifically attention and learning difficulties, arose as a core problem for these children. The outcome of the children at school age showed that for some children developmental problems already were identified, because of their attendance of schools for special education or need for grade retention. Other behavioral problems or psychopathology, also may already have been identified by school age, through use of regular care facilities by parents or schools.

In this chapter will be presented for how many moderate preterm children at school age diagnoses or worries concerning developmental and learning problems were indicated by their parents or teachers. Next, the subgroups of moderate preterm children with and without such problems will be compared concerning their neonatal characteristics. In addition their functioning at school age will be compared on the measurements used in our study regarding IQ, sustained attention, and behavior problems. This information may elucidate what kind of developmental problems are found among moderate preterm children and what neonatal characteristics may carry a higher risk. In addition, it may clarify if most children identified through our measurements with low IQ or problems with sustained attention or behavioral problems, were already identified by their parents or teachers, in that they already had a diagnosis or a need for school adjustment before we examined them around 8 years of age. These analyses may result in important information for the design of follow up studies or monitoring procedures of moderate preterm children.

\section{Methods}

\subsection{Participants}

Selection criteria for the preterm children consisted of: a gestational age at birth of 32 through 36 weeks +6 days, no dysmaturity $(<\mathrm{P} 10)$, no NICU admittance needed, no severe congenital malformations, 7-9 years old. The sample was described in detail in an earlier publication [7]. In short, it consisted of 377 children, 52\% boys, with a mean gestation of 34.7 (1.2) weeks and a mean birth weight of 2425 (455) grams. The distribution of 32, 33, 34, 35 and 36 completed weeks of gestation in the preterm group consisted of respectively $6 \%, 11 \%, 20 \%, 28 \%$ and $36 \%$. Birth weight was below 2500 grams in $56 \%$ with two cases below 1500 grams. 


\subsection{Instruments}

All parents completed a background information questionnaire concerning school situation of the index child, family circumstances, life style during pregnancy, and delivery characteristics. Neonatal data of the preterm children were collected from the hospital files. Cognitive abilities of the children were assessed with the Revised Amsterdam Children's Intelligence Test (RAKIT, short version) for 4 to 11 years [26]. The norm score (IQ score) is 100 (SD =15) and the mean for the subtests is $15(\mathrm{SD}=5)$. The test has good psychometric characteristics with an internal consistency coefficient of: 92 and a test-retest coefficient of: 85. A correlation of: 81 was found with a Dutch version of the Wechsler intelligence test - revised [8].

To measure sustained selective attention, the Bourdon-Vos test was used [9]. On a page with 33 horizontal rows of 24 small figures made of three, four or five dots, the children are asked to mark the configurations that consist of four dots, as quickly as possible. Time to complete the rows and the total page is recorded and norm scores have been provided. The validity, sensitivity, and reliability of the test have been found acceptable by the Dutch COTAN organisation that checks test characteristics [10].

Both parents and teachers were asked to complete a questionnaire on competences and behavior problems, the Child Behavior Check List (CBCL) or Teacher Report Form (TRF) [11]. The CBCL and TRF are parallel forms with good psychometric qualities. Scoring provides an assessment of total number of problems, as well as separate scores for internalizing and externalizing behavior problems. A T-score of 60 indicates a cut off for children with many behavior problems, as was found for $15 \%$ of the norm population. A further division allows separate results for dimensions of anxious/depressed behavior, physical complaints, social problems, thought problems, attention problems and aggressive behavior.

Information on school outcome (i.e. attending a grade appropriate for age, grade retention, or attending a school for special education) was obtained from the parental background questionnaire or the CBCL and TRF questionnaires. School problems were defined as either attending a school for special education, or having repeated a grade in the regular primary school.

Diagnoses or worries related to daily functioning of the children were indicated by parents on the background questionnaire, or in comments to the test leaders who could note such information as particularities of the child. Based upon the information provided in these comments, difficulties in functioning were differentiated into 11 specific problems.

1. 'Health' concerned problems like asthma, diabetes, eczema.

2. 'Senses' reflected need for hearing aids or glasses.

3. 'Motor problems' indicated illness of Perthes, difficulties in sitting.

4. 'Concentration problems' were noted when difficulties with sustained attention were mentioned.

5. 'Learning problems' reflected a developmental delay or use of Remedial Teaching.

6. 'Dyslexia' was mentioned as such. 
7. 'Language problems' indicated treatment by a speech therapist, but also problems in reading, spelling or speech.

8. 'ADHD' was mentioned as such.

9. 'Social emotional problems' reflected anxiety, worries concerning sensitivity and it was mentioned as such.

10. 'Autistic Spectrum' was mentioned as problems within the autistic spectrum.

11. 'Behavioral Adjustment problems' indicated adaptation problems and (hyper)-active behavior.

Although for some children more than one problem was indicated, the information was summarized by an experienced health psychologist (ALvB) into one exclusive code that seemed to represent the most important problem for the child: e.g. when a child was attending a school for children with motor problems and both motor problems and concentration problems were indicated, a final code of 'Motor problems' was assigned.

These problems were summarized into three main developmental domains, distinguishing: 1 ) the somatic domain (difficulties related to chronic health problems, senses of perception, motor functioning), 2) the cognitive domain (attention deficit hyperactivity disorder (ADHD), concentration problems, learning difficulties, dyslexia, and language problems), and 3) the social-emotional domain (diagnoses within the autistic spectrum, and social-emotional difficulties). In addition a separate code was entered for problems appearing in school functioning (need for special education, grade retention).

Finally a separate code was entered to identify the children that either had any school problem, or any other problem in one of the domains, as described above, creating two subgroups of children with or without any problems.

\subsection{Procedure}

The participating preterm children were born between 1996 and 1998 in one of seven general hospitals in the south of The Netherlands. The preterm children were selected based upon the hospitals' archives. Their addresses were traced and their parents were contacted and asked for participation.

The study was approved by the Committee of Medical Ethics of the St. Elisabeth hospital in Tilburg and by the committees of the other participating hospitals. The parents gave their written informed consent.

\section{Statistical analyses}

Descriptive information of the groups with and without developmental problems was compared using analyses of variance and chi-square analyses. Group comparisons concerning 
the different outcome measures were done using multivariate and univariate analyses of variance or crossstabs. All analyses were done with SPSS 20.0.

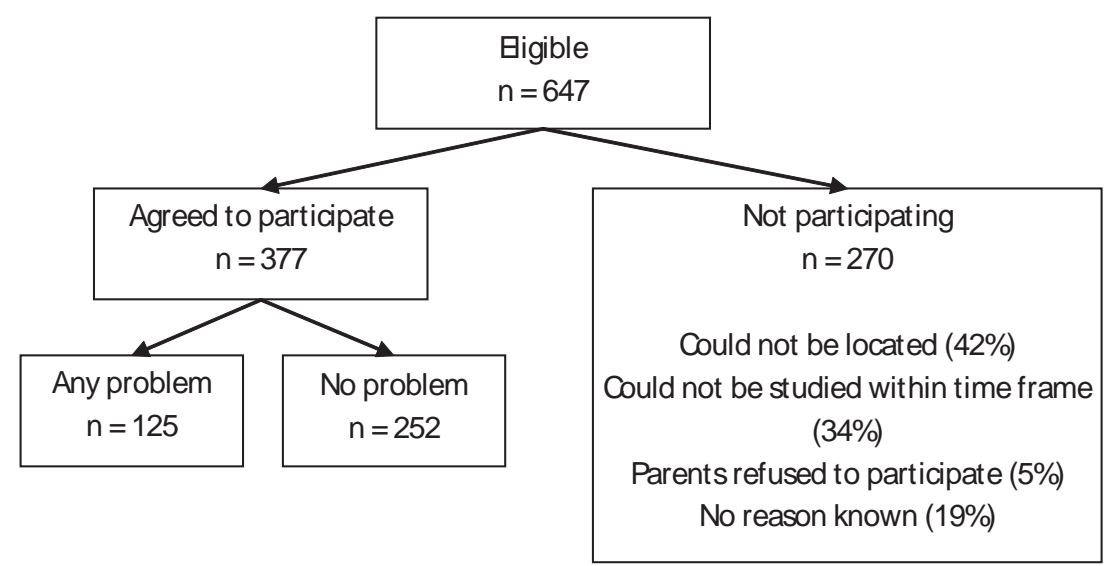

Figure 1. Flow chart of the study design

\section{Results}

Figure 1 presents the flow chart of the study design. It shows that for 252 children no problems and for 125 children any problem had been indicated by parents or teachers when they entered our study. For 13 out of 87 children (15\%) more than one problem had been indicated, e.g. ADHD and behavior problems (coded as ADHD) or motor problems and concentration difficulties (coded as motor problems), but only one code was given.

The amount and kind of developmental problems identified in the moderate preterm children through their school situation and through the diagnoses and worries indicated by parents and teachers are presented in Table 1 per developmental domain and specific kind of problems.

For one third of the moderate preterm children a school or any other developmental problem was found. For $23 \%$ of the total group of preterm children a problem in one of the three domains was identified and for $22.6 \%$ a school problem was found.

Of the children for whom a specific problem in the somatic, cognitive or social-emotional domain was indicated, 47 (54\%) were also found to have a school problem: 22 (25\%) of these children attended a special school and 35 (40\%) (also) had experienced grade retention. For 40 (46\%) of these children no school problems were found. 
For $22(76 \%)$ of the children that attended a special school, and for $35(50 \%)$ of the children that had had a grade retention, a specific problem was identified. For $38(45 \%)$ of the children with school problems, no specific problem in one of the domains was indicated.

Forty children, $14 \%$ of all preterm children without school problems, were identified with a specific problem in one of the domains.

\begin{tabular}{lllc}
\hline Domain & Problem & $\mathbf{N}$ & \% of preterm children \\
\hline Somatic & Health & 16 & 4.24 \\
\hline Senses & Motor functioning & 10 & 2.65 \\
\hline Cognitive & Concentration & 3 & 0.80 \\
\hline & Learning & 8 & 2.12 \\
\hline Dyslexia & 19 & 5.04 \\
\hline Social emotional & Language & 5 & 1.33 \\
\hline & ADHD' & 4 & 1.06 \\
\hline Social emotional problems & 3 & 0.80 \\
\hline Subtotal & Autistic spectrum & 5 & 1.33 \\
\hline School & Behavioral adjustment & 8 & 2.12 \\
\hline Subtotal & & 6 & 1.59 \\
\hline School or other problem & Special education & 87 & 23.08 \\
\hline
\end{tabular}

${ }^{1} \mathrm{ADHD}=$ Attention Deficit/Hyperactivity Disorder

Table 1. Identified problems

In Table 2, the background characteristics and neonatal complications are presented for the subgroups with and without any identified developmental problem. In the subgroup of preterm children with any problem $(n=125)$ significantly more boys were found, chi-square= 11.80, $\mathrm{df}=1, \mathrm{p}=.000$.

A marginally significant effect was found regarding the need for oxygen at any time in the neonatal treatment period, which was needed by more children in the group with any problem, chi-square $=3.75, \mathrm{df}=1, \mathrm{p}=.053$. In the total group of preterm children, oxygen was needed by $23 \%$ of the children, and for $9 \%$ was indicated that they only needed it right after birth. Fifteen children needed oxygen for 3 - 7 days. For the groups with and without problems respectively oxygen only right after birth was needed in $12(11.3 \%)$ versus $16(7.8 \%)$ children, and need for oxygen for 3-7 days in $6(5.6 \%)$ versus 9 (4.4\%) children. 
No differences between the subgroups with and without any problem were found for other indicators of neonatal complications like gestational age, birth weight, hypoglycaemia, need for phototherapy or the duration of hospital treatment. Distribution of 32, 33, 34, 35 and 36 completed weeks of gestation was for the group with problems respectively $8 \%, 13 \%, 23 \%$, $26 \%$ and $30 \%$, and for the group without problems $4 \%, 10 \%, 21 \%, 30 \%$ and $34 \%$, a non significant difference.

The subgroups did differ in parental education of mothers, in that parents of children with problems were less often highly educated; for mothers chi-square $=7.07, \mathrm{df}=2, \mathrm{p}=.029$; for fathers chi-square $=5.86, \mathrm{df}=2, \mathrm{p}=.053$.

These characteristics of the children and their parents were also compared per domain of development, i.e. somatic, cognitive, or social emotional problems, but this did not show any statistically significant differences.

\begin{tabular}{|c|c|c|c|}
\hline & $\begin{array}{r}\text { Preterm } \\
\text { Total group }\end{array}$ & $\begin{array}{r}\text { No problems } \\
N=252\end{array}$ & $\begin{array}{r}\text { Any problem } \\
\qquad \mathrm{N}=125\end{array}$ \\
\hline Boys, n (\%) & $197(52)$ & $116(46)$ & $81(65)^{\star}$ \\
\hline \multirow[t]{2}{*}{ Mean gestation (sd), weeks, range } & $34.7(1.2)$ & $34.8(1.1)$ & $34.6(1.3)$ \\
\hline & $32-36$ & $32-36$ & $32-36$ \\
\hline \multirow[t]{2}{*}{ Mean birth weight (sd), grams, range } & $2425(455)$ & $2448(432)$ & $2380(497)$ \\
\hline & $1340-4130$ & $1340-3564$ & $1530-4130$ \\
\hline Mean days hospital (sd) & $15.7(10.0)$ & $15.2(9.7)$ & $16.8(10.5)$ \\
\hline range & $2-51$ & $2-49$ & $2-51$ \\
\hline Oxygen needed, $\mathrm{n}(\%)^{\star}$ & $71(22.6)$ & $40(19.2)$ & $31(29.2)$ \\
\hline Phototherapy, n (\%) & $162(43.3)$ & $103(41)$ & $59(48)$ \\
\hline Hypoglycemia, n (\%) & $41(13.2)$ & $30(14.3)$ & $11(10.9)$ \\
\hline Multiples, n (\%) & $85(22.5)$ & $64(25.4)$ & $21(16.8)$ \\
\hline \multicolumn{4}{|l|}{ Mothers education, n (\%)* } \\
\hline Primary level & $16(4.4)$ & $8(3.3)$ & $8(6.7)$ \\
\hline Secondary level & $283(78.2)$ & $183(75.9)$ & $100(82.6)$ \\
\hline Tertiary level & $63(17.4)$ & $50(20.7)$ & $13(10.8)$ \\
\hline \multicolumn{4}{|l|}{ Fathers education $\mathrm{n}(\%)^{*}$} \\
\hline Primary level & $11(3)$ & $5(2.1)$ & $6(5.5)$ \\
\hline Secondary level & $235(67)$ & 155(64.9) & $80(72.7)$ \\
\hline Tertiary level & $103(29)^{\star}$ & $78(32.8)$ & $25(22.5)$ \\
\hline
\end{tabular}

Note. Analyses of variance and Chi-square analyses comparing the no problem and any problem groups

${ }^{*} \mathrm{p}<.05$

Table 2. Neonatal and demographic characteristics based upon identified problems 
In Table 3 results are presented for the measurements of intelligence and behavioral problems, when the children were around 8 years old. The results are presented for the subgroups with and without any problem in the first two columns, as well as for the subgroups according to main domain of problems in the last three columns. The number of children that actually show a worrisome level of functioning, i.e. that scored at least one standard deviation below the norm IQ score, or above the cut off for a worrisome level of behavior problems, is presented too.

\begin{tabular}{|c|c|c|c|c|c|}
\hline & No problems & Any problem & $\begin{array}{l}\text { Somatic } \\
\text { domain }\end{array}$ & $\begin{array}{l}\text { Cognitive } \\
\text { domain }\end{array}$ & $\begin{array}{c}\text { Social emotional } \\
\text { domain }\end{array}$ \\
\hline & $M^{1}(s d)^{2}$ & $M(s d)$ & $M(s d)$ & $M(s d)$ & $M(s d)$ \\
\hline $\mathrm{IQ}^{3}$ & $107(13.8)$ & $95(14.6)^{*}$ & $95(16.0)$ & $91(16.6)$ & $101(13.4)$ \\
\hline Sustained Attention & $6.8(2.9)$ & $8.1(2.5)^{\star}$ & $7.7(2.3)$ & $7.7(2.8)$ & $8.2(2.8)$ \\
\hline $\mathrm{CBCL}^{4}$ Total - Mothers & $50(9.2)$ & $57(10.0)^{*}$ & $53(9.4)$ & $58(9.6)$ & 65. (8.1) \\
\hline CBCL Total - Fathers & $47(9.6)$ & $53(10.3)^{*}$ & $51(10.4)$ & $55(9.5)$ & $58(12.4)$ \\
\hline \multirow[t]{2}{*}{ TRF $^{5}$ Total - Teachers } & $50(8.2)$ & $55(8.7)^{\star}$ & $52(8.4)$ & $57(8.2)$ & $62(8.4)$ \\
\hline & N (\%) & N (\%) & N (\%) & $\mathrm{N}(\%)$ & N (\%) \\
\hline $\mathrm{IQ}<85$ & $13(5.2)$ & $29(23.6)^{*}$ & $7(24.1)$ & $13(33.3)$ & $3(16.7)$ \\
\hline Sustained Attention $>8$ decile & $93(37.1)$ & $69(58.5)^{*}$ & $15(51.7)$ & $20(57.1)$ & $11(64.7)$ \\
\hline CBCL Mothers T> 60 & $39(16.2)$ & $45(37.5)^{*}$ & $4(14.8)$ & $17(43.6)$ & $14(73.7)^{*}$ \\
\hline $\mathrm{CBCL}$ Fathers $\mathrm{T}>60$ & $19(8.3)$ & $26(25)^{*}$ & $4(18.1)$ & $11(33.3)$ & $7(46.6)$ \\
\hline TRF Teachers T > 60 & $34(14.7)$ & $38(34.9)^{*}$ & $6(23)$ & $18(48.6)$ & $11(64.7)^{*}$ \\
\hline
\end{tabular}

*Difference between subgroups with or without any problem $=p<.01$

${ }^{1} \mathrm{M}=$ Mean

${ }^{2} \mathrm{sd}=$ Standard deviation

${ }^{3} \mathrm{IQ}=$ Intelligence Quotient

${ }^{4} \mathrm{CBCL}=$ Child Behavior Checklist

${ }^{5}$ TRF $=$ Teacher Report Form

Table 3. Developmental outcome by subgroup based upon identified problems

The subgroups with and without problems differ significantly in all measurements, with lower IQ and more attention and behavior problems for the children whose problems already were identified by parents or teachers (Table 3). This was shown by a multivariate analyses of variance (MANOVA), corrected for sex and maternal education: $F(5,283)=13.62$, $p<.001$, partial eta squared=.194. Univariate analyses of variance showed significant differences for all measurements to the disadvantage of the subgroup with problems. 
In addition, more children in the group with identified problems actually showed a worrisome level of functioning on the IQ test, the sustained attention task and the behavior problem questionnaires answered by mothers, fathers and teachers, as chi-square analyses showed significant differences.

A MANOVA corrected for sex and maternal education showed no significant differences between the subgroups with problems in different domains $\mathrm{F}(10,112)=1.33, \mathrm{p}=.225$, partial eta squared $=.106$. Univariate comparisons did show a difference for the assessment of behavior problems by the mothers, $\mathrm{F}(2,82)=9.85, \mathrm{p}<.001$, and by the teachers, $\mathrm{F}(2,77)=7.69, \mathrm{p}=.001$. These differences indicate that the children with problems in the social emotional domain have more behavior problems than the children who have a main problem in the somatic domain.

As shown by significant chi-square analyses according to mothers and teachers the children who had problems in the somatic domain had less worrisome levels of behavior problems, compared to the children who had a main problem in the cognitive or social-emotional domain.

Only a limited number of children that had a low IQ score $(5.2 \%)$ or a high problem score on the behavior problem questionnaire (ranging from $8 \%$ to $16 \%$ ) were not identified through the comments of their mothers or teachers (Table 3 ).

On the sustained attention task, many children in the subgroup without problems (37\%) also did show difficulties. Attention problems seem to form a general problem for all moderate preterm children.

\section{Discussion}

In this chapter was studied for how many of the 377 moderate preterm children examined at school age, developmental problems had already been identified by parents, teachers or school situation. The developmental problems focussed at, appeared through the children's school problems, placement in special schools, earlier diagnoses, or worries concerning daily functioning as indicated by parents and teachers. For a large subgroup, one third of the moderate preterm children studied, school problems or any developmental problem was indeed identified. For $23 \%$ of the children a specific problem was indicated. These problems consisted for $10 \%$ of cognitive difficulties, for $5 \%$ of social-emotional difficulties, and for $8 \%$ of difficulties in somatic functioning. Attendance of a special school or grade retention was found in $22 \%$ of the preterm children. More than half of the children that were identified with a specific problem, also had a school problem. And, the other way around, for most of the children $(76 \%)$ that attended a special school, and $50 \%$ of the children that had experienced a grade retention, also a specific problem was indicated.

For many children, the difficulties related to school functioning formed their most obvious problem. Beside clear indicators like attendance of a special school, or grade retention, learning problems were also often indicated by parents and teachers and described as difficulties of the child in following the lessons at school. In addition, concentration problems were described in this context. For some children the focus of the description of their problems was put upon 
behavioral adjustment problems. Few children actually already had a formal diagnosis like ADHD or Dyslexia. A number of children (4\%) had mainly health problems, like Asthma, or eczema. This number is not high in view of an estimated prevalence of Asthma in 5-10\% of the Dutch population [12].

Therefore it is concluded that most difficulties of moderate preterm children at school age are captured by an indication of school problems. Several other studies also found a greater risk for difficulties in educational attainment. Preschool readiness testing in Florida in the USA showed that at 5 years of age, $13.6 \%$ of 22.552 late preterm children (34-37 weeks) versus $11.8 \%$ of 164.628 term born children needed special education [13]. In England, risk for not reaching a good level of overall school achievement at age 5 was found to be $12 \%$ and $8 \%$ higher in respectively moderate preterm and late preterm children compared to term born peers [14]. Children aged 5-7 years and born late preterm in the UK, were also less likely to be successful in school attainment assessments [15]. In a Dutch study, small but significant differences between moderate preterm and term groups were found regarding intelligence, attention and executive functioning at 7 years of age, but no differences appeared for verbal memory, and visuomotor and motor skills [16]. Effects were largest in children with low parental education. For somewhat older moderate and late preterm children in England, aged between 8-11 years, was reported that they more often needed extra educational support at primary school than their term peers, but their IQ scores were similar to those of the full term children [17].

Some other studies also looked at specific learning capacities. Concerning 9-13 year old moderate preterm children in New York city, it was found that they had a 30-50\% higher risk of needing special education than full term children. They also had lower adjusted math and English scores than full term children [18]. Also in Scotland, moderate preterm children were found to have a $53 \%$ higher risk of special education needs at primary and secondary school (<19 years of age) compared to term born children [19]. Nomura et al. [20] studied a randomly selected birth cohort $(\mathrm{N}=1,619)$ that was followed into adulthood: IQ and learning abilities were measured in childhood and educational attainment was measured in adulthood. Moderate prematurity was associated with lower educational attainment. In adulthood, approximately one-fifth of the cohort had not completed high school, while one-eighth had some college education.

Other developmental problems are also found more frequently within groups of moderate preterm born children. Data from Danish registers of 20.934 children between 2 and 18 years of age, showed that $37(6,4 \%)$ of 581 preterm children, with gestational ages of $34-36$ completed weeks, had a clinically verified hyperkinetic disorder [21]. Other studies on behavior problems showed higher scores on all Child Behavior Checklist (CBCL) scales for preschool aged moderate preterm children compared to term born children, particularly for girls [22].

In our study on the moderate preterm children whose problems already had been indicated by parents and teachers at 8 years, we looked also at outcomes of the systematic measures that were used in our follow up study, including the CBCL, IQ tests and measure of attention [7]. The subgroups of children with and without any problem indeed clearly differed on all these measures, as shown in Table 3. A large, 12 point difference 
in IQ emerged to the disadvantage of the group with problems. In addition all mean total problem scores on the CBCL as assessed by mothers and by fathers and on the TRF reported by the teachers were more than half a standard deviation higher in the group with problems. On the sustained attention task the subgroup with problems also clearly showed more problems. Therefore, the outcome of these measures seems to validate the worries of the parents and teachers and the school situation of most children.

In relation to the specific domain of problems within the subgroup of children with problems only univariate analyses showed subgroup differences. This may partly be the result from statistical power problems. Large differences in some mean scores did appear: e.g. a 10 point difference in IQ to the advantage of the 19 children with mainly social emotional problems, compared to the 39 children with mainly cognitive problems. On a univariate level the children with mainly health problems were found to have less behavior problems as assessed by their mothers and teachers.

A limitation of this study is that the information regarding earlier diagnoses or worries of parents and teachers concerning the children's development was acquired through rather indirect comments. A more systematic way of measurement, using a specific interview or questionnaire, might have revealed more, or other worries of parents and teachers in greater detail. Nevertheless it seemed important to study this indirect information in order to check what kind of difficulties worried parent and teachers, and if unexpected problems would arise. No such unexpected problems were found, and it is concluded that the general protocol used in the follow up study, that focused upon cognitive capacities, attention and behavior problems, actually reflected the worries of the parents and teachers and the problems of the children.

Another limitation of this study was that the data on neonatal complications had to be collected retrospectively from the hospital files. Nowadays, this information is collected digitally, which may improve systematic reporting. Nevertheless, our findings concerning neonatal complications are similar to other reports, e.g. our sample showed hypoglycemia in $13 \%$ which compares to the $16 \%$ recently reported by Gouyon et al. [23].

In respect to neonatal outcomes, it has been found that in general infants born at 35 to $36+6$ weeks (also indicated as late preterm birth) have more medical problems compared to fullterm infants [24]. In the current study, neonatal characteristics and complications of the groups with and without problems were also compared. Regarding neonatal complications, a small effect was found indicating that the number of children who had needed oxygen was higher in the subgroup with problems. It could be that these early problems in oxygen supply contributed to less optimal brain development which probably has contributed to the developmental problems of these children. Alternatively, other subtle underlying difficulties may have resulted in the premature birth in itself, or in difficulties adapting to extra uterine life (e.g. need for oxygen), which also caused problems in other areas. No other neonatal complications, like hypoglycaemia or need for phototherapy, systematically differed between the two subgroups. Although a trend could be seen that somewhat more children of a younger gestational age were in the subgroup with developmental problems, this was not a statistically significant effect 
An important finding of this study may be that, despite a clear difference between the subgroups with and without problems in the sustained attention task, still many children in the subgroup withóut identified problems had worrisome scores on this task. Attention and concentration problems seem to form a core problem in functioning of moderate preterm children. Other studies also found difficulties in attention capacities of moderate preterm children [6,16]. Sustained selective attention difficulties have already been found to partially mediate the relation between premature birth and developmental outcome [25].

With regard to characteristics of the children, male sex was more frequently seen in the subgroup of moderate preterm children with problems. Many studies have reported higher risk for preterm boys. Adverse neurodevelopmental outcomes, including moderate to severe Cerebral Palsy, mental and psychomotor developmental indices lower than two standard deviations below the norm, were significantly more likely in extremely low birth weight boys than in girls [5]. In Scotland moderate preterm born boys were found to show a more than two times higher risk of special education needs [19]. Possibly boys are more susceptible for neonatal complications that may affect their brain development. Boys are also more often born preterm than girls, as a $7.2 \%$ excess of males was reported for white singleton preterm births and this effect was roughly constant for 20-37 weeks' gestation [26]. Further research on the influence of sex hormones on brain development, starting in the fetal period, and more extensive study on perinatal risk factors in relation to sex of the children, is indicated.

In addition, caretaking processes may differ between boys and girls. Girls may be more sensitive to socialization and stimulation efforts, which may also contribute to differences in developmental outcome, especially in groups at risk. Such processes may also affect development and reinforce or buffer the influence of risk factors.

Another difference found between the subgroups with and without developmental problems concerned parental education. A relationship between developmental outcome and parental education, with more problems in children of lower educated parents, has been reported more frequently. In the study by Cserjesi et al. [16], for instance, small but significant differences between moderate preterm and term groups regarding intelligence, attention and executive functioning were largest in children with low parental education. The relationship with parental education may come about through caretaking and education processes. Parental education however also reflects potentially important genetic and hereditary influences. Further research regarding genetic processes in preterm children is therefore indicated too.

In the group without problems only a limited number of children that had low IQ's or high behavior problem scores were not identified, either through grade retention, need for a special school or explicitly indicated worries of their parents or teachers. An important finding is that many children showed difficulties in the sustained attention task, also in the group without problems. This may indicate that development of attention processes is a sensitive area for all moderate preterm children and further study in this regard is necessary. We did not find many children who had an explicit diagnosis of ADHD, despite the difficulties in attention of many children. Others also found many with attention difficulties, but not with a diagnosis of ADHD, among adolescents born with very low birth weight [27]. Therefore the difficulties in attention skills may be specific for children born with perinatal risk. Further study into specific charac- 
teristics of attention processes in relation to perinatal risk factors needs to be done, preferably already at a young age.

Although it is clear that relatively more very preterm children are affected by developmental problems than moderate preterm children, as reported in the literature [5], many moderate preterm children do show serious difficulties. Therefore, it is important to identify such problems as soon as possible, in order to start preventive activities or treatments. Monitoring of development of moderate preterm children in regular follow up programs is necessary. Follow up should be done at younger ages than school age. A systematic follow up procedure should start already in infancy and at toddler age in order to reduce the consequences wherever possible. Development should be followed in all domains. Especially more extensive monitoring should be done of attention development, as most moderate preterm children are found to suffer from difficulties with sustained attention.

\section{Acknowledgements}

We thank all the parents and children for their participation. The study was conducted in cooperation between Tilburg university, Elisabeth hospital (J. Bruinenberg) and TweeSteden hospital (J. Bonenkamp) in Tilburg, the Catharina hospital (G. Couturier) in Eindhoven, St Anna hospital (B. van den Boezem) in Geldrop, Elkerliek hospital (E. Brouwer and N. Vaessens) in Helmond, Jeroen Bosch Hospital (C. Jacobs and L. Dekkers) in 's Hertogenbosch, Oosterschelde hospital (A. van der Hoop and J. Bauer) in Goes and Christina van Baalen, Eline Beeren, Anouk de Bruijn, Petra Cobussen, Karin Dekkers, Cathalijn Donders, Ilonka van den Heuvel, Petra de Knecht, Anita Rademakers, Elke van Rijsewijk, Kim Seerden, Yasemin Seref, Malou Smits, Marjolein Volaart, Marijke de Wit.

\section{Author details}

Anneloes L. van Baar", Marjanneke de Jong and Marjolein Verhoeven

*Address all correspondence to: A.L.vanBaar@uu.nl

Department of Child and Adolescent Studies, Utrecht University, Utrecht, the Netherlands

\section{References}

[1] Martin JA, Hamilton BE, Ventura SJ, Osterman MJK, Kirmeyer S, Mathews TJ, Wilson EC. Births: final data for 2009. Natl Vital Stat Rep. 2011;60:1-70.

[2] Stichting Perinatale Registratie Nederland. Perinatale zorg in Nederland 2008. Utrecht: Stichting Perinatale Registratie Nederland; 2011. 
[3] De Kleine MJK, Den Ouden AL, Kollée LAA, Ilsen A, Van Wassenaer AG, Brand R, Verloove-Vanhorick SP. Lower mortality but higher neonatal morbidity over a decade in very preterm infants. Paediatr Perinat Epidemiol. 2007;21:15-25.

[4] Raju TNK. Epidemiology of late preterm (near-term) births. Clin Perinatol. 2006;33:751-63.

[5] Saigal S, Doyle LW. An overview of mortality and sequelae of preterm birth from infancy to adulthood. Lancet. 2008;371:261-9.

[6] De Jong M, Verhoeven M, Van Baar AL. School outcome, cognitive functioning, and behaviour problems in moderate and late preterm children and adults: A review. Semin Fetal Neonat M. 2012:17;163-9.

[7] Van Baar AL, Vermaas J, Knots E, de Kleine MJK, Soons P. Functioning at School Age of Moderately Preterm Children Born at 32 to 36 Weeks' Gestational Age. Pediatrics. 2009;124:251-7.

[8] Bleichrodt N, Drenth PJD, Zaal JN Resing WCM. RAKIT Handleiding bij de Revisie Amsterdamse Kinder Intelligentie Test. Lisse, The Netherlands: Swets \& Zeitlinger; 1987.

[9] Vos P.Handleiding Bourdon-Vos test, 3e herziene uitgave. Lisse: Swets Test Publishers; 1998.

[10] Evers A, van Vliet-Mulder JC, Groot CJ. Documentatie van tests en testresearch in Nederland Deel I Testbeschrijvingen. Assen: Van Gorcum; 2000.

[11] Achenbach TM, Rescorla LA. Manual for the ASEBA school-age forms \& profiles. Burlington, VT: University of Vermont, Research Center for Children, Youth \& Families; 2001.

[12] Bindels PJE, Van der Wouden JC, Ponsioen BP, Brand PLP, Salomé PL, Van Hensbergen W, Van Hasselt PA, Steenkamer TA, Grol MH. NHG-Standaard Astma bij kinderen (Tweede herziening). Huisarts en Wetenschap. 2006;49:557-72.

[13] Morse SB, Zheng H, Tang Y, Roth J. Early school-age outcomes of late preterm infants. Pediatrics. 2009;123:e622-9.

[14] Quigley MA, Poulsen G, Boyle E, Wolke D, Field D, Alfirevic Z, Kurinczuk JJ. Early term and late preterm birth are associated with poorer school performance at age 5 years: a cohort study. Arch Dis Child Fetal Neonatal Ed. 2012;97:F167-73.

[15] Peacock PJ, Henderson J, Odd D, Emond A. Early school attainment in late-preterm infants. Arch Dis Child. 2012;97:118-20.

[16] Cserjesi R, Van Braeckel KN, Timmerman M, Butcher PR, Kerstjens JM, Reijneveld SA, Bouma A, Bos AF, Geuze RH. Patterns of functioning and predictive factors in children born moderately preterm or at term. Dev Med Child Neurol. 2012;54:710-5. 
[17] Odd DE, Emond A, Whitelaw A. Long-term cognitive outcomes of infants born moderately and late preterm. Dev Med Child Neurol. 2012:54;704-9.

[18] Lipkind HS, Slopen ME, Pfeiffer MR, McVeigh KH. School-age outcomes of late preterm infants in New York City. Am J Obstet Gynecol, 2012;206:222.e1-6.

[19] MacKay DF, Smith GCS, Dobbie R, Pell JP. Gestational age at delivery and special educational need: retrospective cohort study of 407,503 schoolchildren. PLoS Medicine. 2010;7:e1000289.

[20] Nomura Y, Halperin JM, Newcorn JH, Davey C, Fifer WP, Savitz DA, Brooks-Gunn J. The risk for impaired learning-related abilities in childhood and educational attainment among adults born near-term. J Pediatr Psychol. 2009;34:406-18.

[21] Linnet KM, Wisborg K, Agerbo E, Secher NJ, Thomsen PH, Henriksen TB. Gestational age, birth weight, and the risk of hyperkinetic disorder. Arch Dis Child. 2006;91:65560 .

[22] Potijk MR, De Winter AF, Bos AF, Kerstjens JM, Reijneveld SA. Higher rates of behavioural and emotional problems at preschool age in children born moderately preterm. Arch Dis Child. 2012;97:112-7.

[23] Gouyon JB, Iacobelli S, Ferdynus C, Bonsante F. Neonatal problems of late and moderate preterm infants. Semin Fetal Neonat M. 2012;17:146-52.

[24] Wang ML, Dorer DJ, Fleming MP, Catlin EA. Clinical outcomes of near-term infants. Pediatrics. 2004;114:372-6

[25] Bul KCM, Van Baar AL. Behavior problems in relation to sustained selective attention skills of moderately preterm children. J Dev Phys Disabil 2012;24:111-23.

[26] Cooperstock M, Campbell J. Excess males in preterm birth: interactions with gestational age, race, and multiple birth. Obstet Gynecol. 1996;88:189-93.

[27] Indredavik, M, Vik T, Heyerdahl S, Kulseng S, Brubakk AM. Psychiatric symptoms in low birth weight adolescents, assessed by screening questionnaires. Eur Child Adolesc Psychiatry. 2005;14:226-36. 
